Weber, C.T., and Zornberg, J.G. (2005). Leakage through Liners under High Hydraulic Heads." Geosynthetics Research and Development in Progress, Eighteenth Geosynthetic Research Institute Conference (GRI-18), Austin, Texas, January 26 (CD-ROM).

\title{
Leakage through Liners under High Hydraulic Heads
}

\author{
C.T. Weber ${ }^{1}$ and J.G. Zornberg ${ }^{2}$ \\ ${ }^{1}$ Civil Engineering Department, University of Texas at Austin, Austin, TX 78712; \\ PH (512) 471-5631; FAX (512) 471-6548; email: ctweber@mail.utexas.edu \\ ${ }^{2}$ Civil Engineering Department, University of Texas at Austin, Austin, TX 78712; \\ PH (512) 232-3595; FAX (512) 471-6548; email: zornberg@mail.utexas.edu
}

\section{Abstract}

The overall goal of this project is to contribute towards the use of geosynthetics in the design of dams and other hydraulic systems. More specifically, this project aims at quantifying the leakage through geomembrane and composite liners under conditions representative of dams. Although experimental validation of leakage equations has been conducted, the relatively small head (e.g., $0.3 \mathrm{~m}$ ) allowed over liners for environmental applications has restricted such validation to a narrow range of governing variables. Instead, the use of geomembrane and composite liners for hydraulic systems such as dams involves heads several hundreds larger than those in environmental applications, as well as vertical or near-vertical liner orientations. Accordingly, experimental data is needed to refine the available leakage equations for use in the design of hydraulic systems. An experimental testing program involving quantification of leakage under high heads through geomembranes, soils, concrete and combinations of various other geosynthetics is under way at the University of Texas at Austin. The experimental setup, preliminary results and the scope of additional studies are presented in this paper.

\section{Introduction}

Dams are among the most critical civil engineering structures. They provide an important source of water and energy for agricultural, municipal and industrial use. Geomembranes provide comparatively inexpensive but effective solutions to address problems associated with dam leakage and deterioration. By using geomembranes in dams, the infrastructure of water storage can be protected and its effective service life extended. The hydraulic conductivity of geomembranes (e.g. $10^{-15} \mathrm{~m} / \mathrm{s}$ ) is significantly lower than that of a typical clay (e.g. $10^{-9} \mathrm{~m} / \mathrm{s}$ ). However, the main mechanism of water infiltration through geomembranes involves flow through defects and connections. 
The flow through geomembrane defects has been experimentally and analytically evaluated for liners using hydraulic conditions consistent with landfill applications. Specifically, past studies have evaluated variables that affect the flow of fluid through a composite liner, including subgrade material (soil type), geomembrane thickness, and defect characteristics (Fukuoka 1986; Brown et al. 1987; Walton et al. 1997; Benson et al. 1995). These studies, conducted using cells with diameters ranging from $0.1 \mathrm{~m}$ to $0.6 \mathrm{~m}$, involved testing of horizontally placed layers of geomembrane and soil.

Predicting the leakage rate through a composite liner may require the use of numerical methods. Foose et al. (2001) used 3D numerical modeling to predict the leakage rate and flow characteristics in composite liners. Mathematical models have also been developed to characterize flow through defects (Walton et al. 1997; Rowe 1998). Giroud and Bonaparte (1989) established analytical models for 2D and 3D flow and reported graphical solutions, as well as simplified, empirical equations to calculate the leakage rate. Past analytical studies are in principle only suitable for horizontally-oriented systems.

\section{Experimental Testing Program}

Dams are subjected to large water heads (height of water in the reservoir), particularly when compared to the maximum allowable head permitted by federal regulations in landfills $(0.3 \mathrm{~m})$. Therefore, evaluation of the effect of high water pressure on a flawed geomembrane has been, at best, limited. Other aspects that are also unique to the flow pattern through liners in dams include the construction material, the presence of geosynthetic layers beneath the geomembrane and the fact that mechanical connections, used to attach the geomembrane to the structure, are usually involved. These aspects are also being investigated as part of the ongoing study at the University of Texas at Austin, which is being conducted as a research activity of the Center of Polymers in Hydraulic Systems (CPHyS) of the Geosynthetics Institute (GSI). Dams often have vertical or near-vertical facing, so gravity has a different role in the system when compared with landfills, especially when drainage layers are being considered. Consequently, orientation of the liner is an important factor to be considered in this testing program.

Specific objectives for the experimental program are:

1. Quantify the leakage rate through a geomembrane liner using material combinations typical of dam systems.

2. Quantify the effect of hydraulic head for values that are realistic for dams and evaluate the suitability (or not) of techniques developed for low heads (for verification purposes).

3. Quantify the effect of orientation of the liner system on flow (ranging from horizontal to vertical).

4. Gather experimental data needed to validate models to be developed for prediction of flow rates. 
5. Evaluate the significance of "intimate contact" on the flow rate through liners subjected to high hydraulic heads.

6. Evaluate the advantages and disadvantages of different strategies for the design of geosynthetic liners on the upstream face of dams. For example, evaluation to determine if leakage should be permitted and immediately removed from the system (e.g., using geocomposite drains behind the geomembrane) or if leakage should be restricted or minimized (e.g., using GCLs behind the geomembrane).

Evaluation of the leakage characteristics and the factors that affect leakage is expected to lead to identification of measures that will minimize the flow and deterioration of dams. The experimental program is being conducted in two phases. The first phase includes small-scale testing, using a permeameter cell with a diameter of $0.15 \mathrm{~m}$, which is being used to evaluate the design of the experimental setup. Specific issues being evaluated during Phase I include details on how to secure and seal the geomembrane over the soil sample and how to measure the outflow (the values are expected to be very small). Also, procedures are being developed for sample preparation and saturation and for effective use of soil moisture and suction monitoring devices. Phase II will involve a larger permeameter (approximately 60 $\mathrm{cm}$ in diameter) than that used for Phase I. Phase II aims at representing more closely the actual conditions present in prototype hydraulic systems.

The following variables are considered in Phase I:

1. Hydraulic head: Tests are being conducted for heads ranging from $0.3 \mathrm{~m}$ to $60 \mathrm{~m}$. The flow rates measured using $0.3 \mathrm{~m}$ of head will be compared with the data reported from previous studies on landfill liners.

2. Geomembrane characteristics: The characteristics of the geomembrane will also be varied during the experimental program. 40-mil and 60-mil linear low density polyethylene (LLDPE) and 60-mil high density polyethylene (HDPE), both smooth and textured, will be utilized in the tests to determine the influence of these factors on the characteristics of the flow through the system. Additional thicknesses may be included in this study in the future.

3. Underlying material: Tests are being conducted using the following combinations:

a. Geomembrane/geotextile/concrete

b. Geomembrane/geocomposite drainage layer/concrete

c. Geomembrane/GCL/concrete

d. Geomembrane/soil

e. Geomembrane/geotextile/soil

f. Geomembrane/geocomposite drainage layer/soil

g. Geomembrane/GCL/soil

The tests involving soil will evaluate the impact of soil properties (e.g., hydraulic conductivity) on the flow through a composite liner.

4. Defect characteristics: Common defects include defective seams due to the welding process and penetrations that occur during construction. Seam defects are thin, rectangular slits and holes can be modeled using circular 
shapes. The influence of the defect characteristics on the leakage rate through the system will be evaluated.

5. In-plane drainage properties of the underlying material

6. Liner orientation: Tests will be conducted using various liner inclinations that are applicable to dam liners.

7. Initial water content (for cases involving soil): Water infiltration through a soil layer is influenced by the degree of saturation. The effect of the soil initial moisture condition on the flow characteristics through a soil will be investigated.

\section{Materials \& Equipment}

As mentioned, a wide range of geosynthetic materials are being considered for the experimental program. The soil used as reference for the tests involving soil layers is a silty loam.

Circular holes placed at the center of the permeameter cell are being used for initial validation of available analytical equations. However, defects of different shapes and sizes will be evaluated in the future.

A permeameter cell has been constructed of clear acrylic (Figure 1). The cell is split into two parts, the bottom part of which would contain the soil or concrete specimens. The cell is suitable for conducting tests with both horizontal and vertical flow. The geomembrane is placed between the two sections and sealed using O-rings at the cell interface. The ends contain O-rings to provide a water-tight seal. A porous stone is placed at the bottom of the mold and water inlets are situated at the top and bottom of the cell. A pressure panel is used to control hydraulic heads in the system, as well as for measurement of the outflow. Figure 1 shows the Mariotte device that will be used for maintaining a constant head for the smaller hydraulic heads (less than $3 \mathrm{~cm}$ ).

An important aspect of this laboratory testing program is that not only flow, but also the advancing moisture front in soil, GCL and concrete will be evaluated. The matric suction and/or water content in the soil layer, concrete, and (if possible) GCL beneath the geomembrane will also be measured.

Several approaches are being considered for monitoring the moisture behind the geomembrane. This includes time domain reflectometry (TDR) probes, which measure the dielectric constant of the soil from which the water content can be determined. Tensiometers are also being considered, as they measure directly the matric suction in the soil. Finally, heat dissipation units (HDUs) are also being considered, as they measure the thermal conductivity that relates to the matric potential in the soil.

Each of these monitoring devices has limitations. TDR probes lose accuracy when the water content approaches saturation. Tensiometers are comparatively large probes in relation to the experiment setup discussed herein (particularly considering 
the need of using multiple probes to fully monitor three-dimensional flow configurations). However, a smaller tensiometer is being developed that may be useful for this testing program. The smaller tensiometers will also allow measurements of positive pore pressures that may be generated during infiltration. Because of the limited ranges for different soil moisture measurement devices, a combination of several types of probes is being considered. This will permit measurement over a larger range of soil moisture.

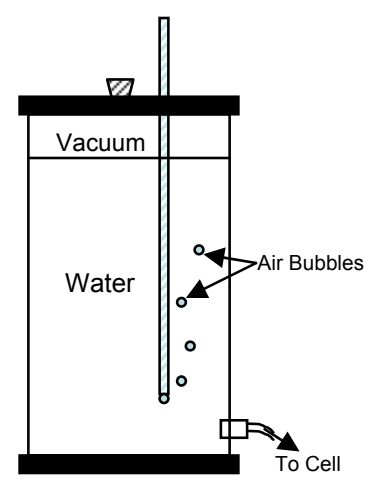

(a)

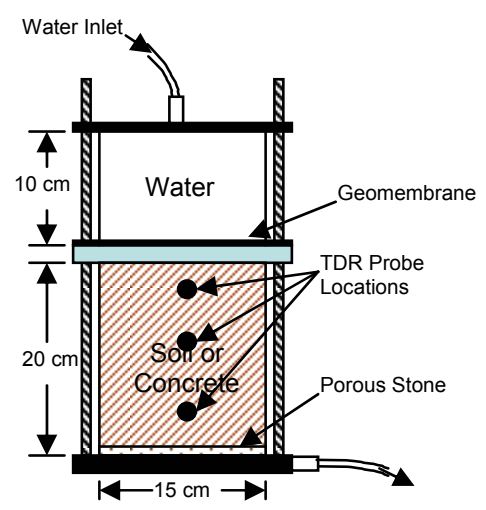

(b)

Figure 1. (a) Mariotte bottle used to supply constant hydraulic head; (b) Permeameter cell with TDR probe locations.

\section{Results and Analysis}

Initial tests were conducted involving geomembranes placed directly on a soil sample. A 40-mil LLDPE geomembrane was penetrated with a drill to create a circular defect with a diameter of $1.8 \mathrm{~mm}$. The silt loam was compacted to a dry density of $1.3 \mathrm{~g} / \mathrm{cm}^{3}$ with an initial gravimetric water content of $7.3 \%$. A Mariotte device was used to apply a constant head of $53 \mathrm{~cm}$ to the specimen. Three TDR probes were placed at elevations of $5 \mathrm{~cm}, 10 \mathrm{~cm}$ and $15 \mathrm{~cm}$ from the bottom of the cell (total sample height was $23 \mathrm{~cm}$ ). The data obtained using the TDR probes can be used to evaluate the advancement of the wetting front through the soil (Figure 2). Figure 1 shows the location of the TDR probes.

The interface between the geomembrane and the soil was initially evaluated considering poor "intimate contact." The Green-Ampt model of 1D infiltration was used to compare the flow through a geomembrane with a defect with the flow through an uncovered system (i.e., no geomembrane). The Green-Ampt solution is obtained using the information on saturated hydraulic conductivity, initial and final volumetric water contents and ponded water height. The saturated hydraulic conductivity of the silty loam is $4.7 \times 10^{-4} \mathrm{~cm} / \mathrm{s}$ at the target density.

The comparison between the Green-Ampt prediction with the experimental data is shown in Figure 3. The figure shows a time lag of approximately 25 minutes 
between the advancement of the wetting front. This time lag can be attributed to the 3D configuration of flow combined with the filling of gaps at the geomembrane-soil interface. However, the Green-Ampt model yielded a wetting front that advanced through the soil layer at a remarkably similar velocity (about $6 \mathrm{~cm} / \mathrm{min}$ ) as the experimental results. Since the test was designed with a poor "intimate contact" between the geomembrane and the soil, the water infiltrated the system at a similar velocity as if the geomembrane were not present at the soil surface. These results appear to validate the approach of using a simple one-dimensional model to predict the advancement of water through a liner system.

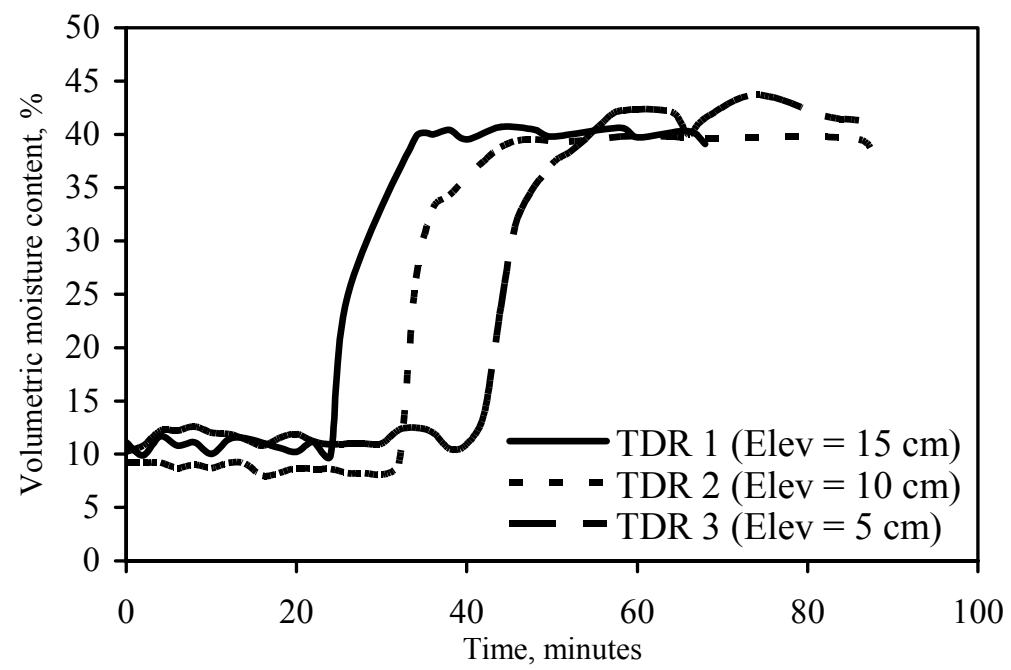

Figure 2. TDR probe measurements for a silt loam under $53 \mathrm{~cm}$ of hydraulic

head.

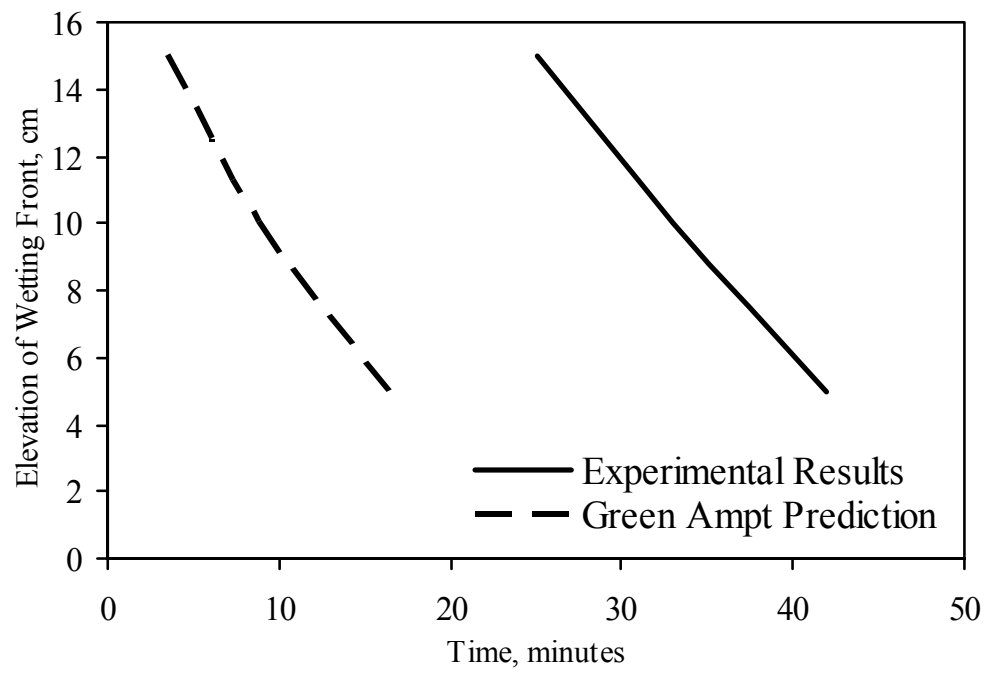

Figure 3. Comparison of wetting front advancement from TDR measurements and Green-Ampt solution. 


\section{The Path Forward}

The initial tests indicate that, under low hydraulic heads, poor "intimate contact" between the geomembrane and underlying soil has a significant impact on the infiltration of water through soil. However, high hydraulic heads are expected to improve the quality of the contact, turning an initially poor "intimate contact" into a subsequent good "intimate contact." Although high heads are also expected to increase the quantity of flow through the system (i.e., higher gradient), the anticipated beneficial "sealing" effect of high pressures is expected to be significant. Further testing is underway to determine the flow patterns and magnitude under various hydraulic needs. The impact of using geotextiles, geocomposite drains and GCLs on the quality of the interface contact and flow magnitude is also under investigation.

\section{References}

Benson, C.H., Tinjum, J.M., and Hussin, C.J. (1995). "Leakage rates from geomembrane liners containing holes." Proc. Geosynthetics '95, Industrial Fabrics Association International, Minneapolis, 745-758.

Brown, K.W., Thomas, C.J., Lytton, R.L., Jayawickrama, P. and Bahrt, S. (1987). "Quantification of leak rates through holes in landfill liners." Rep. No. EPA/600/2-87/062, US EPA, Cincinnati, OH.

Foose, G.J., Benson, C.H., and Edil, T.B. (2001). "Predicting Leakage through Composite Landfill Liners." J. Geotech. and Geoenvir. Engrg., ASCE, 127(6), 534-539.

Fukuoka (1986). "Large scale permeability tests for geomembrane-subgrade system." Proc. $3^{\text {rd }}$ Int. Conf. on Geotextiles, Vienna, 917-922.

Giroud, J.P. and Bonaparte, R. (1989). "Leakage through liners constructed with geomembranes - Parts I and II." Geotextiles and Geomembranes, 8(1) and 8(2), 27-67 and 71-111.

Rowe, R.K. (1998). "Geosynthetics and the minimization of contaminant migration through barrier systems beneath solid waste." Proc. $6^{\text {th }}$ Int. Conf. on Geosynthetics, International Geosynthetics Society, Minneapolis, 27-102.

Walton, J., Rahman, M., Casey, D., Picornell, M., and Johnson, F. (1997). "Leakage through flaws in geomembrane liners." J. Geotech. and Geoenvir. Engrg., ASCE, 123(6), 534-539. 